Artigo

\title{
Aula 1 de Pendurela: Como inventar uma docência em matemática pela reescrita de si?
}

\author{
Lesson 1 of Pendurela: How to invent a teaching in mathematics by self rewriting? \\ Lección 1 de Pendurela: ¿Cómo inventar una docencia en matemáticas por la reescritura \\ de sí?
}

\author{
Grace Da Ré Aurich ${ }^{1}$ \\ [0000-0003-0715-5243] \\ Samuel Edmundo López Bello² \\ [0000-0002-3857-9121]
}

\begin{abstract}
Resumo
Derivada de uma pesquisa de doutorado em uma perspectiva que se afasta do estruturalismo e se inspira nas filosofias da diferença, a Aula 1 de Pendurela intenciona mostrar um processo de caráter singular de diferimento de sentidos, de produção de diferença para a invenção de uma docência em matemática, que consiste na repetição da escrita de si. O processo de reescrita constitui-se como uma experimentação filosófica que acontece ao recolher instantaneidades de uma docência em meio à vida coladas no Vidário de Pendurela e que, ao serem reescritas, têm seus clichês raspados, desse modo, criando uma docência outra a partir do arranjamento entre os conceitos de Escrita de si em Foucault e de Repetição em Deleuze. Prescrições de docências-dadas foram desestabilizadas pensando-se a potência de uma docência em meio à vida, que difere continuamente sem se fixar por ser unívoca. Desse modo, mostrou-se a invenção de uma docência em matemática que evidencia os conceitos de devir, vontade de potência e univocidade na problematização dessa invenção pela reescrita de si.
\end{abstract}

Palavras-chave: Docência em Matemática. Reescrita de si. Diferença e repetição. Singularidade.

\begin{abstract}
Derived from a doctorate research in a perspective that is detached from structuralism and inspired by the philosophies of difference, the main objective of Pendurela's lesson 1 is to show a specific character process of differing meanings and producing differences for the invention of teaching in mathematics, which consists in the repetition of self writing. The rewriting process is constituted as a philosophical experimentation that takes place when grasping unique moments of teaching amid the live affixed in Vidário de Pendurela. While those lives are rewritten, each of them is deprived of their clichés, creating yet another teaching resulting from the arrangement between the concepts of Self Writing in Foucault and Repetition in Deleuze. The prescriptions of teachings given were disassembled considering the power of teaching within living, which differ continuously, not establishing themselves for being univocal. Thus, the invention of teaching in mathematics exhibited the concepts of becoming, the willpower, and univocity in the context of problematization of this invention by self rewriting.
\end{abstract}

Keywords: Teaching in Mathematics. Self Rewriting. Difference and Repetition. Singularity.

\footnotetext{
${ }^{1}$ gracepraktike@gmail.com, Doutora em Educação pela UFRGS, Professora de Matemática na Educação Básica da Rede Estadual de Ensino do Rio Grande do Sul, Escola Estadual de Ensino Médio Luiz Maria Ferraz - CIEP, Bagé/RS/Brasil.

2 samuel.bello@ufrgs.br, Doutor em Educação Matemática pela UNICAMP, Professor Titular do Departamento de Ensino e Currículo da FACED/UFRGS, Professor do Programa de Pós-Graduação em Educação e do Programa em Educação em Ciências da UFRGS, Universidade Federal do Rio Grande do Sul - UFRGS, Porto Alegre/RS/Brasil.
} 


\section{Resumen}

Derivada de una investigación doctoral en una perspectiva que se aleja del estructuralismo y se inspira en las filosofías de la diferencia, la Lección 1 de Pendurela tiene la intención de mostrar un proceso de carácter singular en que difieren sentidos, a fin de producir de diferencia para la invención de una docencia en matemáticas, a partir de la repetición de la escritura de sí. El proceso de reescritura se constituye como una experimentación filosófica que ocurre cuando se recopilan momentos instantáneos de docencia en medio de la vida pegadas en lo Vidário de Pendurela y que, cuando reescritas tienen sus clichés raspados, por lo tanto, creando una docencia otra a partir del arreglo entre los conceptos de Escritura de sí en Foucault y de Repetición en Deleuze. Prescriciones de docenciasdadas han sido desestabilizadas al pensar en la potencia de una docencia en medio de la vida que difiere continuamente sin estabelecerse porque es unívoca. De esta manera, se mostró la invención de la docencia en matemáticas, que destaca los conceptos de devenir, voluntad de potencia y univocidad en la problematización de esa invención mediante la reescrita de sí.

Palabras claves: Docencia em Matemáticas. Reescritura de sí. Diferencia y repetición. Singularidad.

\section{Uma outra escrita, uma outra docência}

Dentro e fora do espaço institucional escolar, podemos pensar como professores encontram-se envolvidos em práticas discursivas que trazem consigo modelos pedagógicos de conduta já dados, prontos, estipulados que acabam por nomear e fixar docências cujas prescrições terminam por conduzir a ação pedagógica docente.

$\mathrm{Na}$ área da Educação Matemática, existem investigações sobre o tema, pesquisadas por um viés que se afasta do estruturalismo, como a organizada em Jelinek, Bello e Santos (2017), que problematizam a constituição de práticas pedagógicas e a própria constituição docente, destacando os efeitos de relações de poder e verdade que as constituem e regulam.

Nessa linha de pensamento, ao pesquisar as redes discursivas na constituição de práticas pedagógicas, em estágios de docência na formação inicial de professores de matemática, Lenzi (2008) evidenciou os efeitos de poder e verdade na constituição e regulação dessas práticas ao perceber, por exemplo, na escrita de planejamentos de ensino de licenciandos estagiários, identidades docentes vestidas em suas intenções de práticas para a sala de aula.

Focando na constituição moral do bom professor de matemática, AURICH (2011), ao problematizar a composição de condutas desse docente, através de jogos de verdade e práticas regradas pelas quais professores podem vir a medir sua prática pedagógica, destacou a vinculação de verdades das ciências como a Pedagogia, a Matemática e a Psicologia do Desenvolvimento à escrita regrada do planejamento de ensino de licenciandos estagiários em matemática.

Santos (2009), em seu trabalho sobre a constituição de licenciandos em Pedagogia, na modalidade a distância, através do que nomeou de dispositivo pedagógico "portfólio de aprendizagens", percebeu, nas narrativas das alunas-professoras, que "[...] há, sim, ditos e escritos que trazem consigo discursos entendidos como verdades absolutas em relação ao papel da reflexão na sua autoformação, ao papel da matemática em seu ensino [...]" [grifo nosso] (p.77).

Nesse artigo, entendemos tais verdades pedagógicas que podem prescrever condutas como clichês - os penduricalhos de Pendurela - que colocam a docência em matemática como algo já dado na área da Educação. Eles expressam docências-dadas, constituídas de elementos 
previamente determinados que, quando tomados como verdades absolutas por professores, reproduzem modelos de conduta, limitando o movimento de produção de singularidades na docência e a criação de outros modos de ser professor ao fixar modos de ser e de agir a algo que lhe é referente.

Entendemos como prescritivas as docências-dadas, isto é, aquelas constituídas principalmente a partir de verdades das ciências da Psicologia e da Educação, docências predicadas e enunciadas como: docência-reflexiva, docência-construtivista, docênciainterdisciplinar, docência-tecnológica, docência-lúdica, docência-inovadora, docências-isso-eaquilo.

Nesse sentido, no momento da escrita deste texto, consideramos que procede a inspiração à uma outra escrita e a discussão acerca da invenção de outras docências. Primeiramente por se preocupar em ofertar outros modos de se pensar uma escrita para produzir sentidos e não, para que venha a fixar significados.

E, também, para destacar a potência possível e que se torna mais evidente na ausência ou na quebra de modelos pedagógicos, da fixidez de seus contornos que, até então eram possíveis e recorrentes, antes da docência sofrer com o momento atual, com a pandemia do COVID-19. Esse cenário, no qual a Educação mundial está inserido, tornou a possibilidade de invenção de outros modos docentes uma necessidade dos dias atuais.

Momento propício para a discussão da docência em meio à vida como ela se encontra: nos "entres" de instituições escolares fechadas, de aulas remotas (que não são as mesmas de uma educação à distância), de portarias, de resoluções e demais documentos legais que procuram regular as práticas pedagógicas para que sejam efetuadas, de procuras por modos de alcançar as formas de docências-dadas, por modelos que não se encontram disponíveis para funcionar em sua forma. São entres em meio a um caos que se apresenta, compreendidos como espaços que se constituem como vetores potentes para a criação, atualmente ainda mais urgente, ao mesmo tempo em que dissolve docências-dadas, dando possibilidade de movimentos à docência em matemática.

Inspirado em leituras das filosofias da diferença que resultaram na produção de uma tese de doutorado, este escrito tem como objetivo mostrar e pensar com um processo de invenção de si, através de uma reescrita de si realizada por Pendurela pode vir a compor uma docência em matemática cujo principal disparador de movimentos na produção de singularidades é a própria vida.

Disparados pelos encontros dados em uma docência em meio à vida, por estar-se atento às instantaneidades vividas, por elas deixar-se afetar e dispor-se a produzir diferimento de sentidos na docência em matemática, trazemos a produção de singularidades na docência por meio da repetição da escrita de si - a reescrita de si.

Enquanto tomamos a docência por uma via discursiva, na qual entendemos que se falamos em algo, também o inventamos e o instituímos, pois esse algo só pode ser pensado em íntima dependência e correlação com o que pode ser "dito", Pendurela movimenta-se, em meio ao texto, trazendo vida e voz a uma docência em matemática, como uma composição linguística que mescla o verbo "pendurar" com o pronome "ela". O verbo faz referência aos penduricalhos discursivos pedagógicos que pesam sua existência ao fixarem e tomarem a docência como dada, pronta e acabada, enquanto que o pronome está ligado ao fato da palavra docência ser um substantivo feminino.

A aula 1 discute a reescrita de alguns trechos das páginas de o Vidário de Pendurela (AURICH, 2017) o qual se trata de um diário de vida docente constituído de fragmentos 
escritos de vivências dadas por meio de encontros que envolvem a docência em matemática na vida na qual acontecem, movimentando-se em um plano de imanência em que o inesperado emerge como elemento de ligação entre aquilo que é dado e o devir produzido a partir desses encontros, compostos e entendidos como uma criação literária de ficção. Esses escritos de instantaneidades do vivido constituem-se como disparadores para o exercício de pensar e repetir uma escrita de si da qual é composta a experimentação filosófica apresentada.

A reescrita aqui proposta mostra-se como uma experimentação filosófica que se afasta da escrita de si que objetiva construir aprendizagens e identidades para reinventar docências. Ela acontece ao recolher e colar instantaneidades de uma docência em meio à vida, raspando seus clichês e criando uma docência outra - o processo de reescrita de si - a partir do arranjamento entre os conceitos de Escrita de si em Foucault e de Repetição em Deleuze.

Não intencionamos, neste texto, ensinar um único caminho, de prescrever outro modelo de docência que, ao se fixar, cristaliza-se como mais um dos penduricalhos a ser carregado pela docência de Pendurela. A aula 1 é outra e vem evidenciar a possibilidade de espaço de produção de diferença na docência entre prescrições de docências-dadas e que, em meio ao momento atual, no qual a docência é tocada pela desordem, pela ausência de previsibilidade, pela impossibilidade de aplicação de modelos reconhecidos, mostrando a potência que o caos proporciona ao não ser possível ordenar, classificar ou nomear qualquer tipo de aula ou de docência. Isso significa que, a partir do encontro com a escrita deste texto, seja possível criar outras aulas, outras docências.

Também não se trata da síntese de uma tese, ou de uma repetição do mesmo, mas de uma reescrita inspirada por outro encontro com ela, de uma repetição criadora de diferença. Como o próprio trecho de uma escrita de Pendurela intenciona: "Não ficarei neste trabalho, tudo passa. E desejo ser outras, também em outras escritas. Desejo de ser repetida, de dar crias, de dar outras criações." (AURICH, 2017, p. 103).

\section{A dança da Reescrita de si como modo de experimentação filosófica}

Para operacionalizarmos o processo criativo de reescrita apresentado neste texto, escrevemos o Vidário de Pendurela, uma criação literária que se tornou corpo para fazermos uso de sua materialidade para a pesquisa e a experimentação a qual nos propusemos. Foi criado e escolhido não por sua capacidade de conservação, mas pela potência das sensações que duram, pois lê-lo remete-nos à força da vida presente nos momentos em docência vividos por Pendurela, daquilo que Ihe afetou e permaneceu do que lhe disse algo e lhe fez pensar sobre sua docência.

A partir dessa produção de afetação que permanece, na qual os disparadores dos escritos de Pendurela são os encontros acontecidos em sua docência, acabou-se por escrever um texto no qual se encontram apenas atributos sensíveis, pois os detalhes já estão destituídos do instante em que ocorreram. "É só num encontro que um corpo se define. [...] É na intersecção das linhas dos movimentos e dos afectos que ficamos sabendo daquilo de que um corpo é capaz." (TADEU, 2002, p.53-54).

A manifestação escrita da percepção que lhe dá duração, tornando-se um percepto, pode ainda possuir rastros de uma lógica representacional, de um dual da docência, de uma experiência. Desdobra-se, então, no que ela dá a pensar: o afecto que dela pode vir a ser produzido, em um primeiro movimento, como efeito e, em seguida, compondo alguma 
singularidade. O afeto dura atualizando o que não há mais condições para que uma representação capture e venha a se manter.

Manifestando-se por essa via textual, perceptos e afectos, produzem singularidades, elementos para outras estilísticas possíveis de serem pensadas no que diz respeito à invenção de uma docência em matemática, ao criarem duplos quando se dá a reescrita, pois há uma correlação entre as duas escritas, um misto entre atual e virtual, cuja causa é imanente, pois "[...] se atualiza em seu efeito, que integra em seu efeito e que se diferencia em seu efeito." (DELEUZE, 2005, p.46).

Reescrever a si mesmo é um ato que dá abertura para novos encontros que não cessam de acontecer em uma docência em meio à vida, pelos "entres" de inspiração deleuziana, por encontros que definem um corpo, "[...] na intersecção das linhas dos movimentos e dos afectos [...] (TADEU, 2002, p.53-54). Na violência causada pelos encontros acontece a afetação, mostrando a existência de uma força capaz de conduzir-nos para além de uma reação ao que é dado como modo de agir, institucional ou pedagógico.

São tomados fragmentos da escrita de Pendurela sobre docências-dadas colhidas do vivido e colados em seu Vidário, para que o processo de reescrita busque raspar o excesso de clichês, diferindo sentidos e, assim, produzir um espaço de criação para singularidades e invenção de uma docência em matemática:

"A aula está dada". - afirmava, com sua voz empostada, Pendurela aos seus alunos ao bater do sinal para encerrar o segundo horário daquela manhã. Pendurela dá aulas de Matemática há alguns anos e sempre orgulhou-se em afirmar coisas do tipo: "Na minhas aulas mando eu.", "Hoje preparei uma coisa diferente.", "Não podemos parar, temos que terminar o conteúdo", "Eu trabalho com a realidade dos alunos", etc. Hoje, porém, mostra-se fatigada, sem energias, sem vontade de continuar lecionando. Santa Pendurela, tão singela com seus penduricalhos. Talvez nem saiba o quanto Ihes pesam, talvez nem imagine que não os tenha que carregar, talvez nem tenha pensado que nunca foram seus. (Reescrita a partir do encontro com um fragmento de escrita de Pendurela, em seu Vidário, AURICH, 2017).

Prescrições morais, práticas discursivas, verdades pedagógicas, docências prenomeadas, transbordam uma aula, conduzem o modo de ser docente de Pendurela. Ela afirma a aula como dada, mas a aula já estava cheia de penduricalhos, mesmo antes de iniciála. Deleuze (1992) e (2007) afirma que pintores e escritores não pintam ou escrevem sobre superfícies brancas, pois as mesmas já estão cobertas de clichês antes da pintura ou da escrita. Os penduricalhos carregados por Pendurela são os dados que constituem os "clichês" e a levam "[...] a dar uma aula que já está dada, antes que [ela] a dê." (CORAZZA, 2012, p.24).

Estamos nos referindo às docências-dadas, pré-existentes às aulas de Pendurela, que conduzem sua prática pedagógica, já que ela deve "respeitar os ritmos individuais dos alunos", "ensinar a partir de suas realidades", "trabalhar com novas tecnologias", "trazer a matemática para a sala de aula", "tornar as atividades lúdicas", "trabalhar com material concreto", "valorizar a escrita e o rigor matemático", "formar alunos críticos, autônomos, cidadãos para transformar a sociedade", entre outras.

Constituem-se como deveres, como prescrições morais, penduricalhos que pesam e fixam Pendurela com uma boa professora, compelindo-a a medir sua conduta com o que lhe é prescrito, como problematizado na pesquisa sobre a constituição moral do professor de matemática, através de jogos de verdade em Foucault (AURICH, 2011). Tomadas enquanto 
verdades, remetem a identidades, a formas de como e de quais conteúdos devem constar no currículo, de como devem ser ensinados aos alunos, de como uma aula deve ser conduzida e de como deve conduzir-se a si mesmo, como deve proceder pedagogicamente para que sua aula seja considerada uma boa aula, etc.

Verdades pedagógicas da ciência quando entendidas como universais, tomam para si mesmas um caráter imperativo e prescritivo, de âmbito moral , fazendo parte da composição de formas-sujeito e de docências-dadas. $\operatorname{BELLO}(2012$, p.25) destaca que

[...] esses aspectos morais são propostos e sustentados desde o engedramento da modernidade como maneiras de se dirigir não apenas a finitude do homem, sua humanização, por meio da razão, mas também para que se produza o estatuto metafísico da verdade e das regras constituintes das boas ações do agir dos indivíduos acima de seus contextos e finalidades.

Em uma via de produção discursiva, regimes de verdade relacionados com determinadas matrizes de saberes formam um plano de consistência para sustentar práticas pedagógicas, em espaços como a universidade e a escola nos quais circulam saberes e prescrições que fixam condutas, constituem subjetividades, conduzem indivíduos, atualizando formas.

Em uma docência-dada, ocorre uma relação com a verdade que precede as ações pedagógicas. Nas condutas, há a questão ética da docência, na qual há espaço para condutas originadas por uma relação consigo. Uma verdade apresentada, pode capturar ou não a forma-sujeito mediante um jogo de verdade. Para Foucault (2006), seria uma autoconstituição da forma-sujeito através de relações com discursos que organizam condutas. Esse modo pelo qual se dá a autoconstituição de condutas, possibilidade de uma vida singular, de uma estética da existência, é entendido por Foucault como ética e significa

[...] uma maneira de viver cujo valor moral não está em conformidade a um código de comportamentos, nem em um trabalho de purificação, mas depende de certas formas, ou melhor, certos princípios formais gerais no uso dos prazeres, na distribuição que deles se faz, nos limites que se observa, na hierarquia que se respeita. (FOUCAULT, 1984, p.82).

Nos jogos de verdade, mesmo que indivíduos se tornem sujeitos morais, essa relação entre sujeito e verdade pode resultar modos de ser e de agir que resultem a práticas de ação de caráter ético ao implicar uma relação consigo e ao mesmo tempo que se autocontitui, torna-se uma forma-sujeito enquanto sujeito de sua moral e não mais como objeto da prática moral.

Pendurela busca movimentar-se entre modos de ser e de igualar-se a um modelo. Todavia não percebe que, enquanto tenta soltar-se da relação de dever que lhe pesa, presente em algum penduricalho, impedindo outramentos de si mesma, acaba por ser capturada por outra forma-sujeito, de alguma outra rede discursiva, atribuindo-lhe outra identidade.

Apesar da ética, como maneira de conduzir-se, mesmo que Pendurela, nesse jogo com as verdades que lhe são propostas, componha um estilo próprio, ele não é mais suficiente para que uma docência não venha a ser novamente fixada.

Poderia Pendurela, ainda, tendo aquilo que é dado como ponto de partida, sem remeter a docência a um ponto de chegada, movimentar-se entre suas instantaneidades, respirar através dos entre-tempos e, jogando com as forças afirmativas da vida no sentido 
nietzschiano, resgatar algo de seus virtuais no sentido deleuziano, de algo que ainda não se constituiu em um estado de coisas, que mesmo sendo real, ainda não é atual?

Se a aula, o docente, a docência estão/são dados, se a tela do pintor e a folha branca do escritor estão virtualmente repletos de clichês (DELEUZE, 2007), assim como o quadro vazio da sala de aula do professor ao dar uma aula (CORAZZA, 2012), por que não rompê-los e dar espaço à criação?

Com essas questões, pensamos um movimento metodológico-filosófico capaz de produzir singularidades em si mesmo e, com isso, inventar uma docência, entendendo que pensar é "[...] inventar o caminho habitual da vida, é fazer o novo, é tornar novamente o pensamento possível." (COSTA; ROSA, 2006, p.6). Empreende-se, então, uma experimentação do pensamento através do retorno de uma escrita, uma reescrita de uma vida em docência.

O processo de escrita - a experimentação filosófica criada, essa reescrita de si - nesta pesquisa, trata-se de um processo de arranjamento entre as noções de Escrita de Si em Michel Foucault e Repetição em Gilles Deleuze.

A escrita de si que propomos, distanciou-se de uma escrita de si presente no discurso pedagógico e em pesquisas na área da educação que problematizam a escrita de si ao atribuirIhe um caráter metodológico com o objetivo de construir aprendizagens ou para constituir identidades (LEMOS, 2009; LUGLI, 2007; FERREIRA, 2012), mas, sim, como em Foucault, uma escrita como um exercício de pensamento que "[...] dá aquilo que se viu ou se pensou a um olhar possível." (FOUCAULT, 1992, p.1).

Nesse sentido, escrever é mostrar-se, é um modo de oferecer-se ao olhar do outro pelo que é escrito sobre si mesmo. É uma escrita que possui um caráter etopoiético, ou seja, "[...] é operadora da transformação da verdade em ethos" (FOUCAULT, 1992, p.134), ao constituírem-se como elementos de um treino de si.

A escrita constitui um corpo, faz de sua escrita seu respectivo modo de pensar e de viver, pois "[...] a escrita transforma a coisa vista ou ouvida 'em forças e em sangue'." (FOUCAULT, 1992, p.143). E, também, porque

A leitura nos percorre e não faz apenas parte de uma lembrança, torna-se nosso próprio corpo. É preciso que haja uma composição das consultas, das leituras e releituras, das escolhas, enfim, da vida, naquele que escreve e no que escreve. Trata-se de conectar fragmentos por meio da criação de um estilo de escrita. E o corpo que aí se cria, não é um corpo de doutrina, é o próprio corpo daquele que ao ser percorrido pelas leituras se apossou delas e faz sua afirmativa. A escrita pode transformar a coisa vista ou ouvida em batalhas. Ela transforma-se em um princípio de ação. Em contrapartida, aquele que escreve se transmuta em meio a esse emaranhado. (MACHADO, 2004, p.149).

Desse modo, a escrita vai corporificando Pendurela, corporificando sua docência, corporificando sua vida. Do mesmo modo, a repetição da corporificação da docência de Pendurela também se corporifica em outra docência, em outro modo de pensar e de viver, a partir da ação de forças que atuam sobre esses corpos.

A reescrita constitui-se como um processo de repetição da escrita efetuado na própria escrita. Repete-se escrita de Pendurela, efetuando-se na escrita de quem a lê, repetindo e diferindo sentidos na própria escrita daquele que reescreve. Foucault (1992) salienta que escrever é um movimento duplo, de escrita e leitura, pois ao mesmo tempo, aquele que escreve lê sua própria escrita, assim como quando se ouve aquilo que se diz. 
Em movimento, são os elementos singulares ler-pensar-escrever que se dispõem e agem entre si para compor algo outro. São partes constituintes de um processo que não se resume em apenas um dos elementos que o constituem. (TADEU; CORAZZA; ZORDAN, 2004).

A reescrita dá indícios da criação de outro estilo, de um outramento de um "si", não mais de Pendurela, mas de outra vida em docência, sem causar estranhamentos em sua leitura que exijam explicações sobre o reescrito, em função da atualidade dos rastros da representação de docências-dadas ao serem reatualizados pela parte de quem os lê.

\section{A reescrita de si como potência para a invenção de uma docência em matemática}

Resistir à representação de docências-dadas pelo ato de pensar, de escrever e de repetir, assumindo a potência de uma docência em meio à vida para reinventá-la, é um movimento de subversão próprio do experimentar. Para Deleuze o pensamento remete à experimentação e, nesse mesmo sentido, podemos entender que:

1) pensar não é representar (não se busca uma adequação a uma suposta realidade objetiva, mas um efeito real que relance a vida e o pensamento, desloque o que está em jogo para eles, os relance mais longe e alhures); 2) não há começo real senão no meio, ali onde a palavra "gênese" readquire plenamente seu valor etimológico de "devir", sem relação com uma origem; 3) se todo encontro é "possível" no sentido em que não há razão para desqualificar a priori certos caminhos e não outros, todo encontro nem por isso é selecionado pela experiência (certas montagens, certos acoplamentos não produzem nem mudam nada). (ZOURABICHVILI, 2009, p. 53).

Fazer do processo de reescrita uma experimentação para inventar docências quer dizer estranhar o processo de recognição imposto pelos mecanismos da representação e torcê-los, subvertendo a cadeia de sua lógica própria e, para isso, entendemos que se faz necessário entrar na estrutura para fazê-la vazar, ou seja, dela fazer uso para que ocorra a produção de singularidades pelo arranjo operatório da escrita de si em Foucault e da repetição em Deleuze.

O potencial de produção de diferença em uma docência pode ser encontrado na repetição. Isso porque a repetição em Deleuze não significa generalidade, forma vazia da repetição, repetição do Mesmo, aquela que reproduz como prescrição para todos os seres, permitida por leis, como substituição de um termo por outro, amarradas em princípios de identidade como analogia e a oposição, como em situações no qual Pendurela, em seu Vidário (AURICH, 2007), propõe-se a repetir suas aulas dadas ou em que ela diz que realiza atividades diferentes, mantendo semelhanças a outras aulas. Trata-se da própria identidade da diferença e produz singularidades, pois

[...] o ser se diz do devir, a identidade se diz do diferente, o uno se diz do múltiplo etc. Que a identidade não é primeira, que ela existe como princípio, mas como segundo princípio, como algo tornado princípio, que ela gira em torno do Diferente, tal é a natureza de uma revolução copernicana que abre à diferença a possibilidade de seu conceito próprio, em vez de mantê-la sob a dominação de um conceito em geral já posto como idêntico. Com o eterno retorno, Nietzsche não queria dizer outra coisa. O eterno retorno não pode significar o retorno do idêntico, pois ele supõe, ao contrário, um mundo (o da vontade de potência) em que todas as identidades prévias são abolidas e dissolvidas. Retornar é o ser, mas somente o ser do devir. $O$ eterno retorno 
não faz "o mesmo" retornar, mas o retornar constitui o único Mesmo do que devem. Retornar é o devir-idêntico do próprio devir. Retornar é, pois, a única identidade, mas a identidade como potência segunda, a identidade da diferença, o idêntico que se diz do diferente, que gira em torno do diferente. Tal identidade, produzida pela diferença, é determinada como "repetição". (DELEUZE, 2006, p.73).

Como uma característica dos conceitos deleuzianos, a repetição no processo de reescrita opera movimento: sem fixar-se, ao mesmo tempo que se faz, se desfaz, descontínua e instantaneamente. Comporta-se, conduz-se sem equivalências ou semelhanças, desse modo, podemos pensá-la, por exemplo, enquanto conduta, na escrita.

Essa reescrita, como movimento de repetir-se, torna-se a potência daquilo que é único, que não possui equivalente ou semelhante, escapando às prescrições, transgredindo e manifestando singularidades em detrimento das particularidades submetidas a uma lei.

Como o eterno retorno em Nietzsche, a repetição "[...] é uma condição de ação antes de ser um conceito da reflexão." (DELEUZE, 2006, p.138). É a potência afirmativa da diferença, já que, para haver produção do novo é preciso que exista a possibilidade da repetição do modo que constitui passado e, novamente, no presente da metamorfose. O novo será a terceira repetição, por excesso, a repetição do futuro como eterno retorno.

Não no seu fim, a invenção de uma docência, mas no processo de reescrever-se é que reside a potência de singularização da reescrita de si. Constituindo-se como um processo de recursividade, a reescrita de si, ao ocupar-se sobre si mesma, torna-se um devir-texto afirmado em si mesmo como diferença. Desse modo, torna-se mecanismo para pensar repetidamente a partir do diferimento, proporcionando pensar outras coisas, deslocando-se de um ponto inicial, pois a linha de efetuação da singularidade permanece em movimento em cada vez que se reescreve, nunca atingindo uma inteireza.

O movimento da reescrita, condição da dança dos penduricalhos de Pendurela, não permitindo que nela sejam fixados, "[...] implica uma pluralidade de centros, uma superposição de perspectivas, uma imbricação de pontos de vista, uma coexistência de momentos que deformam essencialmente a representação." (DELEUZE, 2006, p.93).

Nesse movimento, percebido pelo deslocamento acontecido, raspa-se o que está dado, evitando a determinação de uma nova instantaneidade que se tornaria um novo clichê para tornarem-se outros posicionamentos, outramentos de "sis", dando visibilidade a outra docência naquilo em que difere de si mesma.

Assume-se, desse modo, o caráter problemático da reescrita, sua possibilidade de torcer afirmativamente a estrutura da escrita de si em si mesma quando da sua repetição. Significa, também, assumir

[...] a impossibilidade de fixar o sentido da docência em uma única escrita que lhe invente, pois o movimento de repetição, de reescrita não tem uma convergência, um fim ou uma finalidade. Ele é, em si mesmo, objeto e o processo de singularização que possibilita, disparado pelos encontros e pelos blocos de sensações por eles causados, a invenção de uma docência. (AURICH, 2017, p. 80).

No movimento de reescrever-se existem infinitas parcelas de sentido da escrita e da docência que se transmutam a partir do seu próprio diferimento. A reescrita, que passa a acontecer a partir dos fragmentos escritos de Pendurela, vivifica a vida ao produzir algo fora 
dos contornos da representação a cada repetição e cria um duplo de diferençiação/diferençação extenso com suas singularidades pré-individuais atualizadas.

Um duplo da escrita que transforma seu "eu literário" sobre si mesmo, imanente a um processo de afetação, provocado pelo escrito e por aquilo que ele causa naquele que o lê e o repete, em um processo de outramento e posicionamento de sis que produz novas atualizações daquela escrita a partir de instantaneidades.

A ação de escrever é um virtual em vias de atualizar-se, nunca pré-determinado e a reescrita a desfaz, a torna provisória, móvel e a mantém em movimento. O principal disparador de singularidades, dentro desse processo da reescrita de si, são os encontros com a própria vida em meio à docência, carregada de virtuais, uma vida "[...] feita de virtualidades, acontecimentos, singularidades." (DELEUZE, 2002, p.16).

Esse reescrever-se, dá-se em um tempo-espaço dinâmico, não linear, não ordenado e estático, mas com saltos, acelerações e diminuições de velocidade, rupturas, expressas em vivências, intensidades e devires, constituindo uma escrita-tempo no qual o impensado se efetua, estilizando, singularizando a docência em meio à vida. A determinabilidade da certeza é suspensa pela afetação da escrita e repetição e criação mostram-se imanentes entre si.

Essa escrita-tempo tenta repetir-se em um entre-tempo que dissolve toda e qualquer tentativa ou posssibilidade de uma determinação final. Mantém o estilo sempre em vias de um fazer-se, desfazer-se, refazer-se. Esse misto de tempo e espaço criado e partilhado com a escrita-tempo, não está no âmbito cronológico, nem na extensividade de um espaço, mas em um espaço-tempo no qual as forças afirmativas da repetição atuam em relação a própria escrita e sua repetição, entre-tempo no qual a pulsação é a diferença.

Em cada retorno da escrita, dá-se visibilidade a uma força afirmativa, a partir da qual a docência se integra, diferenciando-se, na escolha ética proporcionada pela seletividade da repetição. Tomando a reescrita como criação que se relaciona com o dado pela ativação do ato de pensar provocado pela repetição, em seu aspecto de seletividade - o pensamento ético da repetição -, tem-se no ato de reescrever o exercício de pensamento e o esforço em extrair o sensível, os modos inusitados, a força criadora da docência.

Esse esforço trata-se do combate ao excesso de clichês, pois o problema não está na página em branco, mas na página cheia. (DELEUZE, 2007a). É preciso dispensar as categorizações que remetem o pensar à recognição, para dar condições de existência ao surgimento daquilo que não é visto, nem sentido: o impensado.

Reescreve-se para provocar-se a força afirmativa, para tornar visível a ação das forças sobre aquilo que é dado, portanto que ainda não era visível em uma docência em matemática. Aquilo que escapa e que ganha visibilidade na produção de uma nova maneira de escrever, de pensar e de sentir, da ordem da intensidade.

Uma escrita "amaneirada" da reescrita, estranha ao formato científico-acadêmico, por seu aspecto e estrutura não usuais nesse meio, dá visibilidade às forças invisíveis que atuam sobre o corpo da escrita. Uma outra estilística na escrita constitui outras corporeidades, outras relações com o vivido, outros modos de pensar e de viver uma docência.

A escrita faz e desfaz-se, deriva-se e integra-se, produz-se e retorna. Tomar a escrita " $\mathrm{e}$ " a reescrita de si " $\mathrm{e}$ " a próxima reescrita continuamente significa arranjar e rearranjar o ato de escrever-pensar-viver, permitindo outramentos de si para fora das determinações do "eu" e dos predicados. Não é possível predicar a docência, assim como um universal se predica de um singular. (CORAZZA, 2013). Pendurela é a voz de uma docência, mas Pendurela não é toda a docência. 


\section{Dançando com os penduricalhos para inventar uma docência em matemática}

A reescrita de si com Pendurela dança, através de movimentos que se dão entre os engendramentos de pensamentos da docência em meio à vida com conceitos das filosofias da diferença. Dançando em meio à vida, à docência e à filosofia, percebe-se no processo inventivo da repetição, produzindo e diferindo sentidos da própria docência, evidenciando singularidades da escrita, a partir de um modo de pesquisar que se autoconstitui em uma experimentação do pensamento.

Nas próximas linhas, seguem os passos da dança da reescrita de si de Pendurela, da invenção de uma docência em matemática.

"Tudo estava organizado: alunos em grupo, material solicitado em cima das mesas, papéis coloridos sendo trocados solidariamente entre os colegas menos favorecidos, colas, tesouras, réguas, lápis de cor. Nessa turma há um aluno que desenha muito bem, já fez inclusive desenhos de fotos minhas que fiz questão de postar no facebook para divulgar o trabalho dele, é uma perfeição. Esse mesmo aluno interrompe a atividade: Professora, tenho uma coisa pra lhe mostrar! 'E me apresenta um lápis. Meio incrédula, faço aquela cara de 'e daí? 'em meio ao burburinho da turma que, aproveitando a interrupção, iniciavam a conversar paralelamente, deixando a atividade de lado. Tratava-se de um lápis de cor todo mesclado na ponta com várias cores. O risco é lindo, cores vibrantes, a escrita é macia. Só não tem como escolher a cor que vai pintar o papel, só pintando para saber. Um arraso! [...]" - conta Pendurela, entusiasmada na aula em que procederia mais uma releitura geométrica. (Reescrita a partir do encontro com um fragmento escrito de Pendurela, AURICH, 2017, p.84-85).

Todos os anos letivos Pendurela propõe uma atividade de releitura geométrica de obras de algum(a) pintor(a) ao revisar áreas de figuras planas com alunos do 30 ano do ensino médio. Afirma que repete a atividade porque os alunos participam, porque o resultado tem visibilidade, é bastante elogiado pelos colegas professores e a equipe diretiva da escola quando os trabalhos dos alunos são expostos à comunidade escolar nas feiras de exposição de trabalhos escolares.

- E porque as verdades da psicologia construtivista, no ensino de matemática, nos conduzem a trabalharmos com esse tipo de atividade nas aulas. complementa Pendurela, ao se atravessar à reescrita deste texto com a força de um pensamento em diálogo por não se conter ao perceber seus escritos sendo repetidos pelos autores. (Reescrita-diálogo de Pendurela, recolhida de AURICH, 2017, p. 85).

Porém, dessa vez, surpresa, Pendurela percebe um lápis tornar-se a sensação daquela aula. Tomada pelo inteligível, Pendurela, em sua docência, organiza, ordena e enche-se de tudo que passa a conter em si mesma, recolhendo uma pequena parte da vida, a parte extensa, compondo uma docência por falta, pois ela é a vida menos algo. O que lhe escapa é o não prescrito, algo que não é possível absorver, pois não se apreende por meio da representação: sua virtualidade, sua singularidade.

Dado o encontro, Pendurela muda o planejamento e a atividade. De geometria plana para artes abstratas e tudo mais o que o encontro com aquele lápis causou uma afetação que Ihe deu a pensar: chama o professor de artes para agendarem uma visita a uma galeria de artes, a fazerem uma viagem a um museu entre outros pensamentos disparados. 
- Não há como ser sempre a mesma, ser sempre igual. - pensa Pendurela sobre o ocorrido. (Reescrita-diálogo de Pendurela, recolhida de AURICH, 2017, p. 86).

Sempre regrada em suas condutas docentes, naquele instante, afrouxou-se um pouco das amarras do discurso do uso de materiais concretos, baseado no construtivismo de Piaget, para lançar-se na discussão sobre arte. Pelo menos, nessa aula, a geometria ficou à espera.

No encontro disparado pela vida em meio à aula, o "querer" de Pendurela escolhe mudar a direção da aula, com a força afirmativa do pensamento que vivifica sua docência, aproveitando-se de uma fissura em uma docência-dada, por um lápis e por instantes, pois "[...] não são necessários grandes movimentos, para que haja diferença. A diferença constitui o próprio movimento, sendo o movimento o diferenciador de uma forma" (SANCHOTENE, 2015, p. 98).

- Andava pesada porque sentia que as aulas pareciam mortas mesmo... mas só percebi o quanto, depois de pensar com a seletividade das forças que há no eterno retorno e pensei em jogar com essas forças e acabei mudando o rumo da aula... (Reescrita-diálogo de Pendurela, recolhida de AURICH, 2017, p. 86).

O aparente problema ao andamento da atividade, a interrupção da aula por um aluno, acaba por disparar outra discussão, tornando a aula de Pendurela problemática no sentido de potencializar um devir-ativo pelo exercício seletivo e afirmativo do pensamento.

Realmente, aquilo que pensei que seria um incômodo, um problema, acabou se tornando muito interessante em algo, me fez pensar outras coisas. Mas, confesso mesmo, que me sinto desconfortável quando não sei o que fazer... $e$, agora, entendo o porquê. É tão difícil pensar. (Reescrita-diálogo de Pendurela, recolhida de AURICH, 2017, p. 87).

A docência-dada não suporta a ausência da forma, perde-se, não sabe se comportar sem uma atualidade, sem uma referência externa, não respira sem o intelecto para organizar e ordenar-lhe. Perde-se nas intensidades das forças, exatamente na potência capaz de produzir singularidades e inventá-la com a repetição, vivificando a si mesma.

A vida, vivida em meio à aula, é inexprimível, não há como representá-la. Sair da aula, o verdadeiro problema da docência (CORAZZA, 2012) e que inspira a busca de tantas soluções em pesquisas na área da educação, pode ser possível se vivida em meio à potência de variação que possui, sem ser remetida e amarrada nas docências-dadas, em dados-clichês. Isso porque as práticas docentes não são a docência, mas a docência se atualiza nelas, assim como as singularidades, elas "[...] não são de um docente, mas nascem na vida, nascem de um dia de aula..." (SANTOS, 2015, p. 82).

Talvez isso seja o que realmente me mortifique... esse "ficar" na aula... esse cumprimento de regras, de carnês. Mortificam, pesam, porque são penduricalhos que não são meus, não são de ninguém, nem podem ser da docência porque o sentido dela é ser da diferença.(Reescrita-diálogo de Pendurela, recolhida de AURICH, 2017, p. 86).

Caso Pendurela ignorasse e não se afetasse pela intervenção do aluno, teria "ficado na aula", negado a vida e sua potência criadora, permaneceria fixa em sua docência- 
construtivista, ou outra docência-dada qualquer, contrariando o movimento da vida e, assim, negando a própria univocidade da docência. "Ficar na aula" ao não considerar a vida que ali acontece, nega o caráter problemático e fabricar um problema inexistente em busca de solução que será "[...] um sucesso relativo em relação às condições do problema ou do meio, ela é ainda um fracasso relativo em relação ao movimento que a inventa: a vida [...]." (DELEUZE, 2012, p. 90).

Quando Pendurela modifica sua aula, nota-se um rastro da estilística proposta por Foucault, pois há um movimento para escapar de algo posto e estratificado, as prescrições de caráter moral, esse "ficar na aula", no qual aquilo que está dado "pré-enche" a mesma.

Pensei na questão do imperativo moral presente nas verdades das ciências da educação, principalmente sobre o uso do material concreto e da contextualização dos conteúdos, tão visíveis na docência em matemática e, aqui pensando ainda fica martelando aquela máxima: "A matemática está em tudo." Daí busquei mudar de jogo. De parar de jogar com as verdades $e$ focar em jogar com as forças. (Reescrita-diálogo de Pendurela, recolhida de AURICH, 2017, p. 88).

Porém, Pendurela não intenciona essa mudança a fim de estabelecer uma relação com o outro, como técnica ou cuidado de si e, se o fizesse, isso ainda não a colocaria em devir, apenas a jogaria em outras regras, agora criadas por si mesma. A ação do pensamento de Pendurela constituiu-se por necessidade em uma força que a manteve em movimento no encontro com outro pensamento [sobre o lápis], jogando-a para o devir, para a diferença.

Captar e tornar visíveis as forças que atuam na escrita de Pendurela, também não é algo representável. A reescrita necessita utilizar também uma força, um movimento entre a decomposição e a recomposição de efeitos que decomponha o fragmento da rede discursiva no qual está preso, dando-lhe forma determinada, para recompô-lo em um plano de imanência que lhe atribua potencial para produzir a diferença. É um movimento de "[...] efeito que remete ao mesmo tempo a uma força única que o produz e a uma multiplicidade de elementos decomponíveis e recomponíveis sob essa força." (DELEUZE, 2007b, p. 63).

A deformação age sobre formas em repouso, pois se utiliza da estrutura para transformá-la. Decompondo os fragmentos da docência de Pendurela pela reescrita, percebese que tudo está "[...] em relação com forças, tudo é força." (DELEUZE, 2007b, p. 65).

Depois de pensar em todas essas coisas e conceitos e tudo mais, comecei a dar mais atenção ao inesperado, ao acaso e aos encontros para extrair deles outras maneiras de pensar. Procurar não deixar que o devir-reativo ganhe esse jogo... Mas não é fácil, mais parece uma luta, sem descanso.

(Reescrita-diálogo de Pendurela, recolhida de AURICH, 2017, p. 89).

A potência das forças na reescrita escapa o dado e dissolve predicados da docência de Pendurela. Raspa de modo intensivo a extensividade da escrita de si, pois a força investida no ato de pensar, ao impulsionar uma reescrita, insiste na indeterminação de fronteiras ou contornos de classificação. Isso ocorre porque:

Quando uma força se exerce sobre uma parte que foi limpada, ou raspada, ela não dá origem a uma forma abstrata, assim como não combina dinamicamente formas sensíveis: ao contrário, ela faz dessa uma zona de indiscernibilidade comum a várias formas, irredutíveis a qualquer uma delas, 
e as linhas de força que ela faz passar escapam de toda forma por sua própria nitidez, por sua precisão deformante [...] (DELEUZE, 2007a, p.64-65).

Reescrever deforma a escrita de Pendurela, criando um duplo da escrita, com diferimento e produção de sentidos pois, como a vida, também não são fixos. Nesse duplo, espiraliza-se uma escrita-tempo que, para reescrever-se, necessita olhar para uma aula-tempo que se dá na escrita de Pendurela, captando as forças, transformando sentidos.

Esse tempo Aion de escrita e de docência, como a vida em meio à aula, em uma aulatempo, é devir. É tempo que contém a pluralidade caótica da vida, as intensidades individuantes, as velocidades e lentidões que fazem durar as sensações. Tempo em que a docência percebe a diferença em si mesma, pois só pode ser sentida, viver os dados e os nãodados em movimento, os encontros que se dão. Por mais que uma aula esteja planejada, algo muda, acontece e a forma da docência-dada se esvazia, vaza, é fissurada.

Essa aula-tempo é o que mais me dá agonia e violenta meu pensamento. Porque não consigo controlar tudo o que se dá nesse entre-tempo, não capturo. E, ainda, luto para me desvencilhar desse querer dar conta de uma totalidade, impossível de acontecer em qualquer tempo. (Reescrita-diálogo de Pendurela, recolhida de AURICH, 2017, p. 89).

A escrita de si que se constituiu num corpo é potencializada pela repetição dessa escrita que, ao repetir, difere, deforma, afirmando a única voz da docência: a da diferença. Nesse tempo de intensidades, do devir, do acontecimento, não existem formas, nem identidades. Nele dá-se, pela repetição, um processo singular no qual a docência se efetua na potencialidade da ideia [aquilo que atravessa todas as manifestações criadoras] do pensamento. Isso significa que a escrita-tempo é marcada pela diferença em si mesma.

A reinvenção de uma docência em meio à vida, acontece em um duplo tempo de uma escrita de si - a escrita-tempo (Aion) e o tempo-escrita (Cronos). Tempos distintos e coexistentes, partes de um real e de uma imanência.

No tempo-escrita, extenso, unidirecional, contínuo e sucessivo da docência, uma escrita de si - assim como uma aula - "está dada" (CORAZZA, 2012, p. 23) antes da primeira palavra. A folha está pronta, ocupada, pré-definida por prescrições, formas vazias da diferença. Nele escreve-se a docência com escolhas dadas a partir de conjuntos de teorias e procedimentos esperados, nos quais a docência toma forma na escrita. É o tempo que preenche uma docência das coisas já conhecidas: o plano de aula, a sala de aula, os alunos,

[...] os modos de ver e falar; posições de sujeitos; regimes de signos; palavras de ordem; imagens de pensamento; códigos estriados; funções rígidas; sensações produzidas em sistemas retilíneos; narrativas explicativas e tranquilizadoras; e assim por diante. (CORAZZA, 2012, p. 23)

Reescrever o si de Pendurela é um movimento no qual o "si" torna-se o objeto, reinventa um outramento de si, nesse duplo do tempo, dessa repetição tomada enquanto processo inventivo de uma docência que considera a atualidade e a virtualidade da escrita combinada com a interferência do acaso, com o ainda desconhecido da existência, no qual "[...] o virtual é, nesse sentido, a reserva infinita real de potenciais diferenciadores das estruturas" (SANCHOTENE, 2015, p. 53) da escrita.

No processo inventivo da reescrita há, também, singularidade no modo de conduzi-la, no estilo constituído por movimentos. Nesse sentido, enquanto ato, não há como singularizá- 
lo em algo já dado na existência, logo não há como ser engolido pela representação. Inventar a docência por meio da reescrita de si é prender-se ao seu devir sem recompô-lo de modo artificial, sem imitar a escrita, mas imitar seu devir. (DELEUZE; GUATTARI, 1992).

A reescrita, no sentido imitativo do seu próprio devir, torna-se uma escrita-força que mantém a vibração das virtualidades nos sentidos que prolifera, nos perceptos e afectos que produz. Uma escrita-força que se coloca em movimento pela relação com outra força, a força do pensamento sem pensar a vida em meio à docência na sua potencialidade reativa, movendo-se em direção de uma verdade, de um ideal, de um modelo, de uma forma perfeita, de uma essência, mas sim, ao desejar uma verdade que não deseja o verdadeiro.

Diminuir a docência, controlar a docência, viver uma docência mínima, quer dizer viver uma docência em sobrevida, uma docência-zumbi que se arrasta atrás de modelos, encaixando-se em um jogo ao invés de jogar o próprio jogo, catalogando afetos, ao invés de vivê-los. (Reescrita-diálogo de Pendurela, recolhida de AURICH, 2017, p. 92).

Sendo força, a reescrita possui relação intensa com a sensação, a intensidade da força é o seu poder de afetação. Agindo sobre o corpo da escrita de si, não é a sensação que é sentida, mas sim o que ela "dá" a sentir. Se assim não fosse, como Pendurela poderia escrever o grito do aluno? As conversas paralelas dos colegas? O desenho perfeito do seu aluno artista?

As forças, em relação uma com as outras, em um processo de afetação, num jogo de forças - entre forças ativas, criadoras e forças reativas, dominadas - resultam na vontade de potência. Reescrever Pendurela, inventando uma docência, é vivificar uma docência que quer dizer: "Trair-se as potências fixas que querem nos reter, as potências estabelecidas [...]" (DELEUZE; PARNET, 1998, p.53).

Constituída na composição dos afetos de Pendurela em uma vida docente, ouvir a voz dessa docência é dar visibilidade à intensidade que ela carrega, potencializando a discussão que o constante movimento de diferença em si mesma produz, no qual tudo se dá na docência ao mesmo tempo em que a constitui.

Penso, agora, que importa também realizar um exercício que se aproxima de um desapego dos dados-clichês para poder colocar a docência em movimento, em devir e inventá-la, afirmando sua univocidade. Reclama-se das classificações, das categorizações, dos modos de como fazer, dos códigos, dos modelos, das "10 dicas de como dar uma aula", mas segui-los não assusta. Deveria, mas pelo contrário, tranquiliza. Por quê? (Reescrita-diálogo de Pendurela, recolhida de AURICH, 2017, p. 93).

Porque desobriga a pensar e...

Mas: "Pensar depende de forças que se apoderem do pensamento. Enquanto nosso pensamento estiver ocupado e somente encontrar seu sentido nas forças reativas, ainda não pensamos." (DELEUZE, 1976, p. 15). Então pensar obriga a jogar com as forças. E as forças sabem jogar, são nocauteadoras, porque pensar também é luta. Mas também, nesse jogo-luta, pode-se pensar no inusitado, pode-se pensar em criação e invenção de uma docência, uma vida em docência. Para quê? (Reescrita-diálogo de Pendurela, recolhida de AURICH, 2017, p. 93). 
Para sair do ressentimento, da aula, de uma cultura e de uma formação do(c)entes e da própria mudez das ações reativas que não sabem gritar, da vontade dócil que se perde quando estranha algo, que só sabe viver de encontros marcados e que se esconde do inesperado por não saber caminhar pelo impensado.

Sair da "caixinha" que se fixa em pensar se algo é verdadeiro ou se é falso, nem que por um instante. Sair para pensar, para passear no pensamento, para deixar de negar a diferença, negar os encontros, negar a vida. O que não vale é ficar só com os pensamentos garantidos, seguros, confortáveis e tranquilizadores. (Reescrita-diálogo de Pendurela, recolhida de AURICH, 2017, p. 94).

Escrever e reescrever-se torna-se uma estratégia dessa luta. Em cada movimento de reescrita há uma experimentação que não pode ser generalizada, que tem caráter provisório e rescisório de tudo que está dado na docência.

Reescrever-se suscita questionar-se a cada repetição:

"O que estamos fazendo de nós mesmos?"

(Reescrita-diálogo de Pendurela, recolhida de AURICH, 2017, p. 94).

\section{Recomeçando a aula: a voz da docência, voz da diferença}

Com esta pesquisa, que mostrou a produção da diferença pela via da reescrita de si, buscamos nos afastar de universais pedagógicos e da criação de novos clichês para a docência em matemática. Para isso, nos propomos a dar vida a um modo de pesquisar através de uma experimentação filosófica, pois entendemos, como Zordan (2014), que a maneira de pesquisar diz respeito aos modos de se conduzir, à uma ética e à uma estética.

A experimentação pretendeu evidenciar a invenção de outras docências em matemática, disparar movimentos de pensamento engendrando docência e filosofia e inspirada pela potência da repetição para subvertermos a lógica da representação, desestabilizando docências-dadas sem relativizá-las para pensar a força criadora de uma docência que acontece em meio à vida em na irrepresentabilidade do sensível.

A potência criadora do movimento na reeescrita reside em não buscar significados. Não se reescreve para reconhecer, ou para validar uma verdade, mas para produzir algo que possua sentido, que difira em si mesmo e não na diferença subordinada à oposição, à semelhança ou à analogia.

A voz da docência é a voz da diferença, é unívoca, difere continuamente, em uma impossibilidade de fixação, pois nunca encontra uma totalização, uma inteireza que a represente e que possa vir a ser reconhecida pelo pensamento em qualquer uma de suas infinitas repetições ou mesmo na composição de todas essas repetições.

Na univocidade, "[...] o ser se diz, de todas as maneiras num mesmo sentido, mas se diz assim daquilo que difere" (DELEUZE, 2006, p.417) e, como a reescrita é a repetição no eterno retorno de Nietzsche, no qual a diferença produz repetição ao mesmo tempo em que a repetição seleciona a diferença, entende-se que: "O Ser se diz num único sentido de tudo aquilo de que ele se diz, mas aquilo de que ele se diz difere: ele se diz da própria diferença." (DELEUZE, 2006, p.67).

Entretanto, não se prometeu uma fuga de uma clicherização. Mesmo assumindo a intensidade, a velocidade e a proliferação do pensamento, não há uma vida em docência sem atualizações de movimentos. No corpo que se constitui pela reescrita, está evidente a 
presença do fluxo das forças que sobre ele atuam, a vontade de potência que determina a qualidade e a quantidade de relação entre essas forças (se serão ativas ou reativas), contudo, o pensamento torna-se uma instantaneidade, um posicionamento, que se atualiza ao ser capturado. Não há meios de mantê-los em movimento, mas há como manter-se receptivo às forças afirmativas, aos encontros e, assim, torcer o pensamento.

Essa reescrita, enquanto escrita-força, da qual a docência tornou-se objeto de reinvenção, inventa docências porque provoca outros modos de relacionar-se com a escrita, provoca outros modos de viver. Risca a vida e a docência com um lápis-devir, cujo seu encontro de cores torna indeterminável a cor do próximo risco, de definir ou fixar uma pintura ou uma escrita de vida, pois o devir não imita, não identifica-se, nem proporciona relações formais, porque o devir é, partindo do que se tem e do que se é, "[...] extrair partículas, entre as quais instauramos relações de movimento e repouso, de velocidade e lentidão, as mais próximas daquilo que estamos em vias de nos tornarmos, e através das quais nos tornamos." (DELEUZE; GUATTARI, 1992, p.55)

E Pendurela?

Se é possível que um objeto - que não possui vida, pensamento, menos ainda vontade - carregue em si essa potência de variação, quanto mais pode Pendurela variar, criar e inventar uma docência, munida da força do seu pensamento e da vontade de afirmar a vida, efetuando, assim, a equação "querer = criar"? (AURICH, 2017, p. 101).

A partir dos encontros com a vida, docência e filosofia, Pendurela permitiu-se deslocar, por instantes e por diferimento, das docências-dadas e dos dados-clichês, pela experimentação da escrita que Ihe produziu efetuações do pensamento. Saiu do repouso, da inscrição em modelos que não admitem um devir-docência e colocou-se em movimento pela força do pensamento, abrindo a possibilidade da liberação de forças mais criativas para produzir outros modos de pensar e de viver, outros modos de "docenciar".

O verbo criado por Pendurela, docenciar, ganha sentido nesse processo inventivo da reescrita de si que afirmara vida em meia à docência, assumindo sua potência criadora e os encontros disparadores do pensar fora dos limites da representação, efetuando um agir que contém uma seletividade ética, característica da univocidade da docência, da voz única que é diferença pura, diferindo, assim, sentidos para a docência e, com isso, possibilitando outramentos dos modos de vivê-la.

Porque é o que a reescrita produz. Reescrever-se possibilita não fixar o sentido da docência por pensamentos que remetam ao dado pré-constituído, conformado com os modelos e na segurança de agir pelo reconhecimento, mas tomar como impulso do pensar a afetação causada pelos encontros. A raspagem dos clichês pela reescrita de si dá visibilidade às forças capazes de dar vida a uma docência, só sendo possível pela via da experimentação.

Pendurela repetiu-se na vibração que dura, ficou mais leve, com menos deveres que pesam, ao ser afirmativamente receptiva aos devires que the permitem voar quando escolhe jogar com as forças do pensamento em Deleuze, lendo Nietzsche, ao invés de jogar com as verdades, em Foucault.

A aula 1 sempre recomeça e não se encerra, pois a imanência permanece em um continuum de espaço-tempo no qual a reescrita de si utiliza seu lápis-devir provocando um riscar rearranjado sempre que acionada na intensidade do ato de reescrever-se. 


\section{Referências}

AURICH, Grace Da Ré. Jogos de verdade na constituição do bom professor de matemática. 2011. 117f. + Anexos + DVD. Dissertação (Mestrado em Educação) - Programa de Pós-Graduação em Educação, Faculdade de Educação, Universidade Federal do Rio Grande do Sul, Porto Alegre, 2011.

AURICH, Grace Da Ré. Reescrita de Si: a Invenção de uma Docência em matemática. 2017. $152 f$. Tese (Doutorado em Educação) - Programa de Pós-graduação em Educação, Faculdade de Educação, Universidade Federal do Rio Grande do Sul, Porto Alegre, 2017.

BELLO, Samuel Edmundo López. As práticas curriculares em Matemática que se produzem pelo governo do IDEB. Horizontes, Itatiba, v. 30, n. 2, p. 10-30, jul./dez., 2012. Disponível em: < http://revistahorizontes.usf.edu.br/horizontes/article/download/58/30 >. Acesso em: 30 jun. 2020.

CORAZZA, Sandra. Didática da criação: aula cheia, antes da aula cheia. In: CORAZZA, Sandra (Org.). Didaticário de criação: aula cheia. Porto Alegre: UFRGS, 2012 (Escrileituras cadernos de notas; 3). p. $23-27$.

CORAZZA, Sandra Mara. O que se transcria em educação? Porto Alegre: UFRGS; Doisa, 2013.

COSTA, Cristiano Bedin da. ; ROSA, Marcele P. . Escrita sobre nada. In: II Seminário Nacional de Filosofia e Educação - Confluências, 2006, Santa Maria. Artigos Completos do II Seminário Nacional de Filosofia e Educação. Santa Maria: Editora Facos, 2006.

DELEUZE, Gilles. Bergsonismo. Trad. Luiz B. L. Orlandi. São Paulo: Editora 34, 2012.

DELEUZE, Gilles. Diferença e repetição. 2ª ed. Rio de Janeiro: Graal, 2006.

DELEUZE, Gilles. Foucault. São Paulo, Brasiliense, 2005.

DELEUZE, Giiles. Francis Bacon: lógica da sensação. Rio de Janeiro: Jorge Zahar, 2007a.

DELEUZE, Gilles. A imanência: uma vida. Educação e Realidade. v. 27, n. 2, p. 10-18, 2002. Disponível em: <http://seer.ufrgs.br/index.php/educacaoerealidade/article/view/31079/19291>. Acesso em: 26 abr. 2020.

DELEUZE, Gilles. Nietzsche. Lisboa, Portugal: Edições 70, 2007b.

DELEUZE, Gilles. Nietzsche e a Filosofia. Rio de Janeiro: Editora Rio, 1976.

DELEUZE, Gilles; GUATARRI, Félix. O Que é a filosofia? Rio de Janeiro: Ed. 34, 1992.

FERREIRA, Geraldo Generoso. A escrita de si como labirinto na construção da identidade profissional docente. Revista de Letras Norte@ mentos, v. 4, n. 8, 2012.

FOUCAULT, Michel. A escrita de si. In: FOUCAULT, Michel. O que é um autor? Lisboa: Passagens, 1992. p. 129-160. Disponível em: <http://eps.otics.org/material/entrada-outras-ofertas/livros/aescrita-de-si-michel- foucault>. Acesso em: 25 mai. 2020.

FOUCAULT, Michel. A ética do cuidado de si como prática de liberdade. In: Ditos e escritos V: Ética, sexualidade, política. MOTTA, Manoel Barros da (org). 2 ed. Tradução Elisa Monteiro e Inês Autran Dourado Barbosa. Rio de Janeiro: Forense Universitária, 2006. p. 264-287. 
FOUCAULT, Michel. História da sexualidade II: O Uso dos Prazeres. Tradução de Maria Thereza da Costa Albuquerque. 10. ed. Rio de Janeiro: Graal, 1984.

JELINEK, Karin Ritter; BELLO, Samuel Edmundo López; SANTOS, Suelen Assunção Santos (Orgs.). Educação Matemática: linguagens, práticas e sujeitos. Porto Alegre: Canto-Cultura e Arte, 2017.

LEMOS, Sandra Monteiro. A "escrita de si" inventando "histórias de vida". Horizontes, v.27, n. 1, p. $91-103$, jan./jun. 2009.

LENZI, Giovana da Silva. Prática de Ensino em Educação Matemática: a constituição de práticas pedagógicas de futuros professores de matemática. 2008. 106f. + Anexos. Dissertação (Mestrado em Educação) - Programa de Pós-Graduação em Educação, Faculdade de Educação, Universidade Federal do Rio Grande do Sul, Porto Alegre, 2008.

LUGLI, Rosário S. Genta; SILVA, Vivian Batista. A escrita de si como alternativa de formação docente: análise de uma experiência. Horizontes, v. 25, n. 1, p.37 - 45, jan./jun. 2007.

MACHADO, Roberto. Deleuze, a arte e a filosofia. Rio de Janeiro: Jorge Zahar Ed., 2009.

MACHADO, Leila Domingues. O desafio ético da escrita. Psicologia \& Sociedade, v. 16, n. 1, p. 146150, 2004. Disponível em: <http://www.scielo.br/pdf/\%0D/psoc/v16n1/v16n1a12.pdf>. Acesso em: 10 jun. 2020.

SANCHOTENE, Virgínia Crivellaro. A impossibilidade da permanência: conversas com Foucault e Deleuze. Porto Alegre: CANTO: Cultura e Arte, 2015.

SANTOS, Suelen Assunção. Docenci/çação: do dual ao duplo da docência em matemática. Porto Alegre, 2015. 196 f. Tese (Doutorado em Educação). - Programa de Pós-graduação em Educação, Faculdade de Educação, Universidade Federal do Rio Grande do Sul, Porto Alegre, 2015.

SANTOS, Suelen Assunção. Experiências narradas no ciberespaço: um olhar para as formas de se pensar e ser professora que ensina matemática. 2009. 123f. Dissertação (Mestrado em Educação) Programa de Pós-Graduação em Educação, Faculdade de Educação, Universidade Federal do Rio Grande do Sul, Porto Alegre, 2009.

TADEU, Tomaz. A arte do encontro e da composição: Spinoza + Currículo + Deleuze. Revista Educação \& Realidade. v. 27, n.2, jul./dez. 2002. Disponível em:

<http://seer.ufrgs.br/index.php/educacaoerealidade/article/view/25915/15184> Acesso em: 25 jun. 2020.

TADEU, Tomaz; CORAZZA, Sandra; ZORDAN, Paola. Linhas de escrita. Belo Horizonte: Autêntica, 2004.

ZORDAN, Paola. Das maneiras de se escrever uma pesquisa. Revista Digital do Laboratório de Artes Visuais, Santa Maria, v. 7, n. 2, mai./ago. 2014. Disponível em: <http://cascavel.ufsm.br/revistas/ojs2.2.2/index.php/revislav/article/view/15109/pdf_1 >. Acesso em: 11 abr. 2020.

ZOURABICHVILI, François. O Vocabulário de Deleuze. Trad. André Telles. Rio de Janeiro: Relume Dumará/Sinergia: Ediouro, 2009. 